\title{
Natural Convection of a Solar Wall in a Test Room under Tunisian Climate
}

\author{
N. Dimassi and L. Dehmani \\ Laboratoire des Procédés Thermiques, Centre de Recherches et des Technologies de l'Energie, Technopôle de Borj-Cédria, \\ BP 95, 2050 Hammam-Lif, Tunisia \\ Correspondence should be addressed to N. Dimassi, dimassinarjes@yahoo.fr
}

Received 13 April 2012; Accepted 9 May 2012

Academic Editors: E. R. Bandala and B. Mwinyiwiwa

Copyright ( $\odot 2012$ N. Dimassi and L. Dehmani. This is an open access article distributed under the Creative Commons Attribution License, which permits unrestricted use, distribution, and reproduction in any medium, provided the original work is properly cited.

\begin{abstract}
Tunisia has a great potential of solar energy, which is the most important source of renewable energy; however, sufficient benefit can be obtained from this clean energy source especially for building heating. This paper reports on an experimental investigation on the natural convection of a Trombe wall in a test room located in Borj Cedria under the Mediterranean climatic conditions of Tunisia. Temperatures were recorded throughout the test room, as were the air velocity and the climatic parameters affecting the Trombe wall operation. This work deals with analyzing the natural convection heat transfer process with the evaluation of Rayleigh number, Nusselt number, the wall convection coefficient, and the convective flux. The results show that many parameters affect the wall function and therefore the thermocirculation process. The flow along the wall was found to be composite and turbulent most of the time.
\end{abstract}

\section{Introduction}

Energy consumption in building sector is an important factor in the increase of the total energy bill. As a result, considerable interest has been recently acquired to passive solar heating systems [1], which combine solar collection and thermal storage into the building structure and distribute the heat by natural methods. The Trombe wall is a kind of passive solar heating systems used for space heating. The wall is painted black matt and typically located on the south face of the building to maximize its solar exposure throughout the year. The glazing forms an air gap between the wall surface and the outside air. Vents are placed at the bottom and the top of the wall to allow air circulation through the air gap. Solar heat, absorbed by the darkened massive wall surface, is transferred to the room by convection and conduction. The heat is collected and stored in the massive wall during the day and propagates through the wall to reach the building space at night. The thermocirculation provides a direct heat path to the building. The stack effect pulls colder air in at the bottom vent and pushes warmer air (heated by the wall) out at the top. Considering the winter season, the application of Trombe walls is still problematic because of different design aspects [2]. Energy and air movement in the gap of the Trombe wall is induced by natural convection. Akbari and Borgers [3] and Fedorov and Viskanta [4] performed a theoretical analysis of the laminar natural convection between two parallel plates and obtained velocity and temperature fields. Aung et al. [5] conducted a numerical and experimental investigation of developing natural convection flow in a vertical duct with asymmetric side wall for both constant heat flux and constant temperature boundary conditions. The effect of channel width on natural convection between vertical parallel plates was studied experimentally by Sparrow and Azevedo [6]. They found that heat transfer was reduced dramatically if the channel width had the same order of magnitude as the boundary layer thickness. For a typical building to avoid flow blockage effects, the channel width should be greater than $4.7 \mathrm{~cm}$ [7]. Sandberg and Moshfegh [8] performed experiments on the channel flow using two vertical parallel walls heated from one side. The relation 
between the measured air flow rate and heat flux rate was found to follow a power law. They also used a numerical method to study the effects of heat flux rate and channel width on the convective heat transfer in the channel [9]. The flow rate through the channel was found to increase with width. Chen et al. [10] examined the airflow in a Trombe wall and presumed that the airflow is a function of air duct height. In another study by Sodha et al. [11], the thermal performance of Trombe walls and roof pond systems was investigated for passive heating and cooling of a building. Raman et al. [12], in their study, they developed a passive solar system, which can provide thermal comfort throughout the year in composite climates. A parametric study given by Gan [13] has shown that airflow rate was almost unaffected by channel width; however, airflow rate was increased with the wall height. He proposed that using double glazing could increase the flow rate by $11-17 \%$. Thus, the design parameters of Trombe wall channel are also factors that might affect the convection process [14]. The work of Hami et al. [15] consists of the modelisation of the natural convection flow in a room heated by the technique of a ventilated Trombe wall. They used the computational fluid dynamics technique (CFD) for air flow simulation in the solar chimney and studied the influence of solar chimney depth variation on the thermal efficiency of the system. The fluid temperature distributions and flow patterns in scaled test cell with Trombe wall were examined in the experimental work of Warrington and Ameel [16]. The natural convection flow process occurring in the air gap of the Trombe wall is fairly complex. Studies in the literature on free convection between heated vertical plates deal mainly with theoretical and numerical solutions for laminar flow with either constant heat flux or constant temperature surfaces and the obtained theoretical formulas are complex and not practical for the engineering calculation. In addition, the incident solar intensity is not constant and periodical and the interior values of temperature and velocity depend on its intensity. Besides, the numerical model can't describe the real situation scientifically. Studies reveal that the problem needs for a lot of experimental data under specific climatic conditions, and a full understanding of heat and fluid flow mechanism still requires optimization to achieve efficient use. Therefore, there is a need to further study of convection heat transfer in Trombe walls under different climatic conditions that extremely affect the thermal performance of the Trombe wall. In this study, the experiment of a test room with Trombe wall is carried out under the Tunisian climate, where solar radiation is abundant and offers a high potential of energy.

\section{Theoretical Study}

In solar walls, the heat transfer and the fluid flow are closely coupled phenomena. Calculations of wall surface temperatures, convective heat transfer coefficients, and air velocity need to be performed at the same time in an integrated way. An analysis of the heat transfer and the air flow phenomena inside the air gap involves a number of correlations that can be chosen for the wall convection coefficient.
2.1. Physical Properties of Air. The air physical properties are assumed to vary linearly with air temperature because of the low temperature range encountered. The following empirical relationships are proposed based on tabulated data from Incropera and DeWitt [17] for air properties between 300 and $350 \mathrm{~K}$ :

dynamic viscosity:

$$
\mu_{f}=\left[1.846+0.00472\left(T_{f}-300\right)\right] \times 10^{-5},
$$

density:

$$
\rho_{f}=1.1614-0.00353\left(T_{f}-300\right),
$$

thermal conductivity:

$$
\lambda_{f}=0.0263+0.000074\left(T_{f}-300\right),
$$

specific heat:

$$
C p_{f}=\left[1.007+0.00004\left(T_{f}-300\right)\right] \times 10^{3},
$$

volumetric coefficient of expansion:

$$
\beta_{f}=\frac{1}{T_{f}} .
$$

2.2. Convective Heat Transfer Coefficients. We are interested to the heat transfer between the wall and the glazing, $h_{g}$ and $h_{w}$ are, respectively, the convective heat transfer coefficients between glazing and the fluid and the wall and fluid. These coefficients are calculated through the Nusselt number $(\mathrm{Nu})$ :

$$
\begin{aligned}
& h_{w}=\frac{\mathrm{Nu}_{H w f} \cdot \lambda_{f}}{H}, \\
& h_{g}=\frac{\mathrm{Nu}_{H g f} \cdot \lambda_{f}}{H},
\end{aligned}
$$

where $\mathrm{Nu}$ depends on the Rayleigh number ( $\mathrm{Ra}$ ) and the Prandtl number ( $\mathrm{Pr}$ ) being the latter dependent only on the type of fluid. The Rayleigh number depends on the temperature difference between the surface and the fluid

$$
\mathrm{Ra}=\mathrm{Gr} \cdot \mathrm{Pr},
$$

where

$$
\begin{aligned}
\mathrm{Gr}_{w f}= & \frac{\beta_{f} g \rho_{f}^{2} H^{3}\left(T_{w}-T_{f}\right)}{\mu f^{2}}, \\
\mathrm{Gr}_{g f}= & \frac{\beta_{f} g \rho_{f}^{2} H^{3}\left(T_{g}-T_{f}\right)}{\mu_{f}^{2}} .
\end{aligned}
$$

If $\mathrm{Ra}<10^{9}$ the flow is laminar and $\mathrm{Nu}$ is calculated according the correlation of Churchill and Chu [18] is

$$
\mathrm{Nu}=0.68+\frac{0.67(\mathrm{Ra})^{1 / 4}}{\left[1+(0.492 / \mathrm{Pr})^{9 / 16}\right]^{4 / 9}} .
$$

If $\mathrm{Ra}>10^{9}$ the flow is turbulent and $\mathrm{Nu}$ is given by:

$$
\mathrm{Nu}=\left[0.825+\frac{0.387(\mathrm{Ra})^{1 / 6}}{\left[1+(0.492 / \mathrm{Pr})^{9 / 16}\right]^{8 / 27}}\right]^{2}
$$




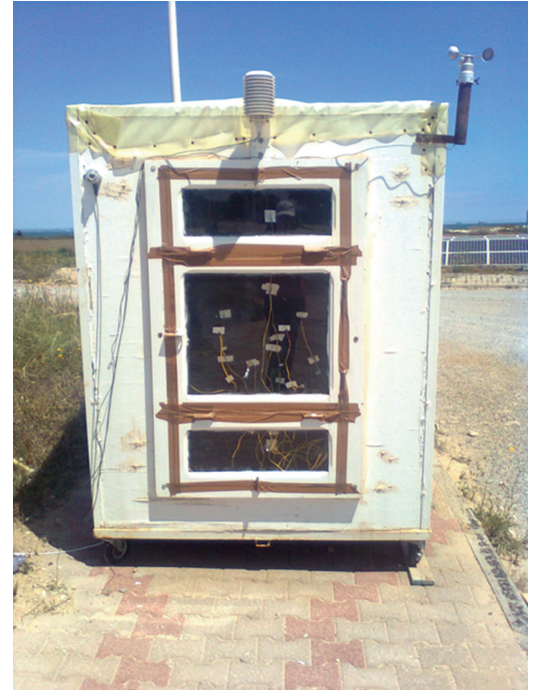

FIGURE 1: Experimental test room.

\section{Experimental Set up}

The experiment has been executed in a test room with Trombe wall located at the Laboratory of Thermal Processes (LPT) in the Center of Research and Technology Energy (CRTEn) in Borj Cedria $\left(36^{\circ} 43^{\prime} 04^{\prime \prime} \mathrm{N}, 10^{\circ} 25^{\prime} 41^{\prime \prime} \mathrm{E}\right)$. The experimental test room shown in Figure 1 consisted of a rectangular box measuring $1.86 \mathrm{~m}$ high $1.52 \mathrm{~m}$ wide $1.52 \mathrm{~m}$ deep and was oriented facing south in order to be exposed to solar radiation. The front of the test room was provided with glazing. The heat absorbing wall located behind was painted matt black and made of $0.10 \mathrm{~m}$ thick concrete brick and its height was $1.65 \mathrm{~m}$. The glazing cover and the heat absorbing wall formed a $0.12 \mathrm{~m}$ air gap. The vents at the bottom and the top of the massive wall through which air circulates from the room to the air gap were $0.15 \mathrm{~m} \times 0.25 \mathrm{~m}$. The top, base, and side walls were fabricated from $0.2 \mathrm{~m}$ of wood thickness and $0.4 \mathrm{~m}$ thick of polystyrene panel.

In order to measure temperature, chromel alumel thermocouples were positioned at 4 points along the heat absorbing wall, 3 points along and in the middle of the air gap and 2 points on the glazing as shown in Figure 2. Silver paper was used to prevent direct sunshine projecting all probes. The air velocities of the vents were measured using a hot-film anemometer T.S.I model 8455 Air Velocity transducer located at the centre of each vent. The outdoor air temperature and the relative humidity were measured using the temperature and humidity transmitters HD 9008 TR. The wind speed was measured by an anemometer $13 \mathrm{~N}-$ 219-S34. Solar radiation intensity was recorded with the KIPP-ZONEN CM-21 Pyranometer. The data above was all collected every 5 minutes then saved in the computer with a data-logger device. The test was performed in December 2011 when heating needs increase significantly in Tunisia since the monthly mean ambient temperature is less than $20^{\circ} \mathrm{C}$.
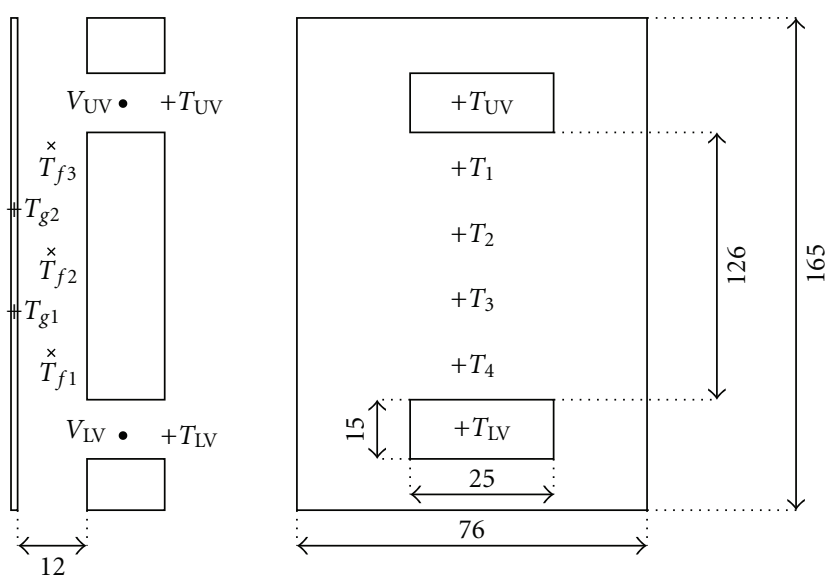

FIgURE 2: Position of testing probes and dimensions of the Trombe wall in $\mathrm{cm}$.

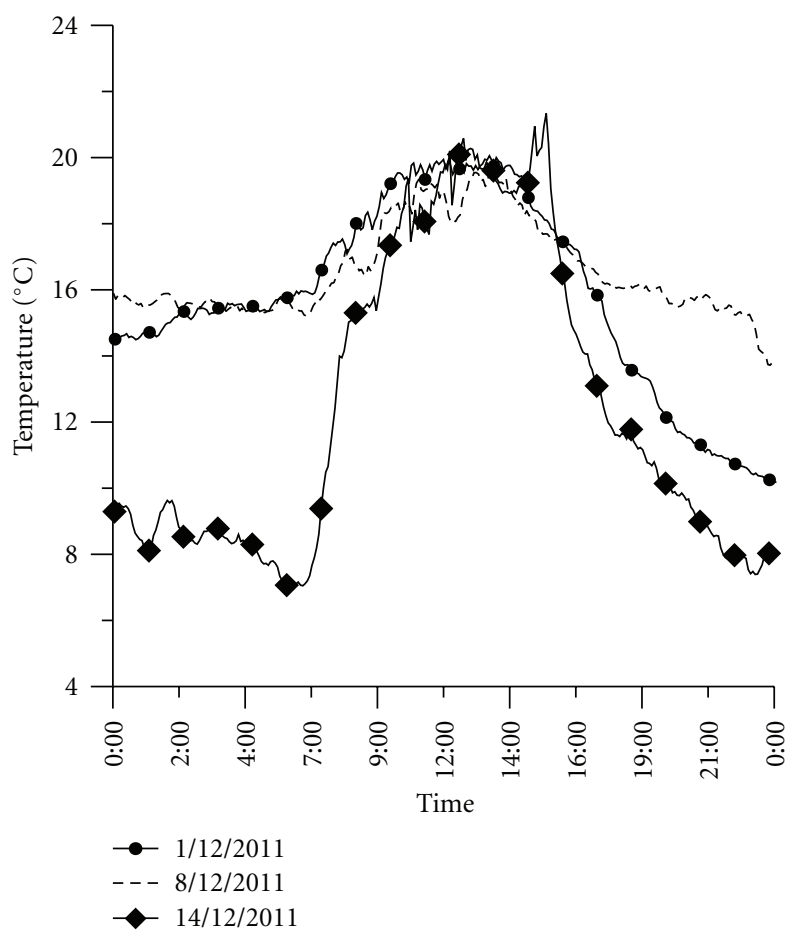

FIGURE 3: Evolution of outdoor temperature on December 1th, 8th, and 14th 2011.

\section{Results and Discussion}

4.1. Climatic Conditions. In order to investigate the dominant influencing factors of the Trombe wall thermocirculation phenomenon during the day time, experimental data from three different days of three different weeks on December 2011 are used. The climatic parameters affecting the Trombe wall operation are essentially the outdoor air temperature and the solar radiation. The evolution of outdoor air temperature and solar radiation intensity for December 1th, 8th, and 14th are given in Figures 3 and 4. As can be seen on Figure 3, the diurnal difference of 


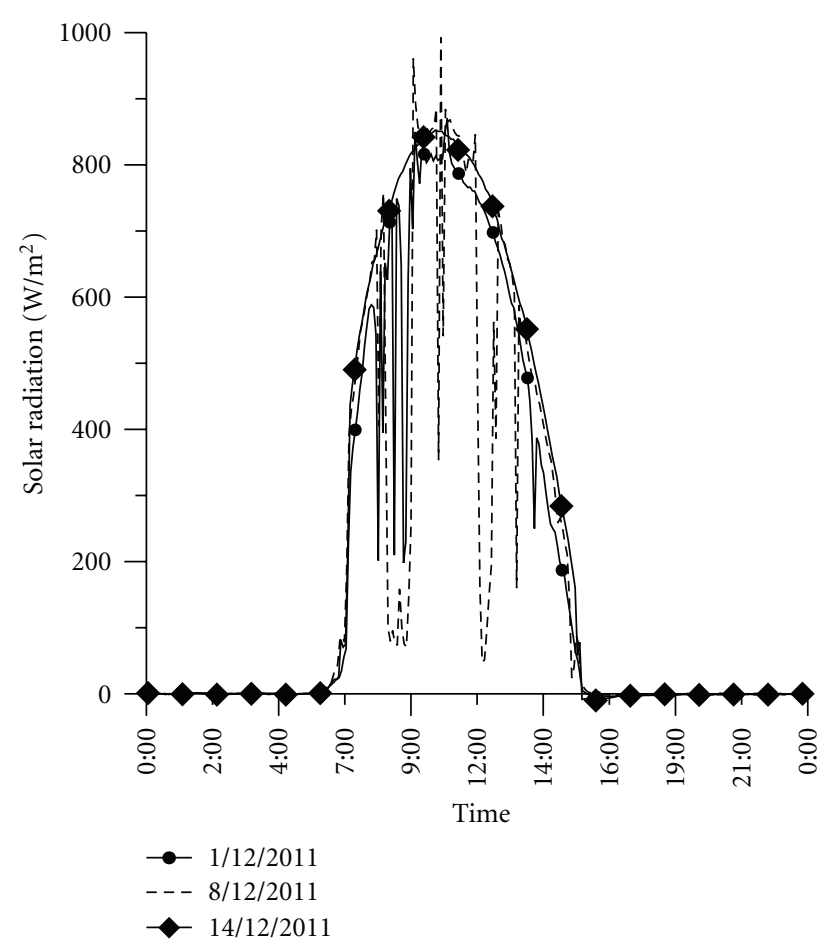

FIgURE 4: Evolution of solar radiation on December 1th, 8th, and 14th 2011.

temperature for the days of $1 / 12 / 2011$ and $8 / 12 / 2011$ is about $4^{\circ} \mathrm{C}$ while for $14 / 12 / 2011$ this difference is $14^{\circ} \mathrm{C}$. The maximum outdoor air temperature during the day time is between 19.5 and $21^{\circ} \mathrm{C}$. The 8/12/2011 shows an example of a low-radiation day with climatic disturbances (Figure 4). During this day, climatic disturbances were observed; they are correlated to the presence of heavy clouds which induce great variations of solar radiation intensity. In this situation, the solar radiation intensity can vary suddenly between 350 and $1000 \mathrm{~W} / \mathrm{m}^{2}$. The $14 / 12 / 2011$ represents a clear and sunny day with a maximum of solar radiation about $852 \mathrm{~W} / \mathrm{m}^{2}$. On $1 / 12 / 2011$ the weather is unsettled: there were some light clouds from 7:00 to 9:00 and then the sky remains clear. Therefore, these days are a good representation of the possible weather situations during Tunisian winter.

\subsection{Evolution of Test Room and Trombe Wall Temperature.} Figure 5 shows an example of temperature variation during the wall operation period on the sunny day 14/12/2011. We observe that the outer wall surface temperature was the highest and the outside temperature was the lowest, while the test room temperature had a value in between throughout the function period. This result is consistent with the thermocirculation process for the 1/12/2011 and the $8 / 12 / 2011$. It can be seen that glazing and wall temperatures followed the incident solar radiation and were practically always higher than outdoor air temperature which have a big change from day time to night time (Figure 3). The maximum wall temperature was observed around 13:00 and it reaches $52.8^{\circ} \mathrm{C}$. In the afternoon and due to the stored heat

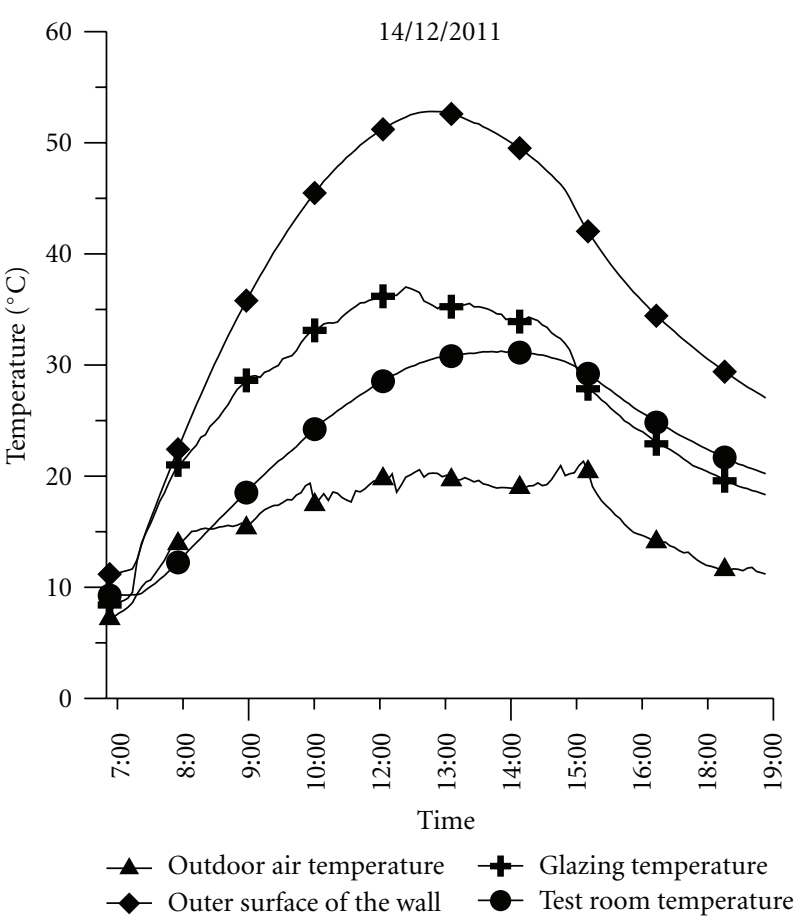

Figure 5: Variation of outer wall surface, glazing, ambient, and inner room temperatures on 14/12/2011.

within the wall, room air temperature was $22.5^{\circ} \mathrm{C}$ at 18:00 despite the decrease of the ambient temperature to $12^{\circ} \mathrm{C}$.

4.3. Effect of Trombe Wall Height and Solar Radiation. In order to assess the performance of the wall, we compare the evolution of temperature at different level of the wall on the three studied days (Figures 6-8). The temperature progress indicates the upward direction of the flow over the wall. The wall temperature increases as we progress along the wall, it therefore heats up the air in the gap which moves to the upper vent and contributes to the heating of the test room dwelling. As excepted the wall temperature evolution is directly influenced by solar radiation on 8/12/2011 (Figure 7), which is a mostly cloudy day. The effect of cloudiness could be apparently observed as fluctuations in the values of the black wall surface temperature. On 1/12/2011 (Figure 6), fluctuations of solar radiation have not affected significantly the evolution of wall surface temperature since climatic changes occurred very early (7:00). At this time, the wall temperature increases gradually.

4.4. Effect of Air Gap Height. We compared air temperature profiles across the air gap depth at different heights during the period of thermocirculation (7:00 to 19:00) for the three studied days (Figures 9-11). The temperature distribution across the gap is dependent upon solar radiation. The air temperature increases as we progress along the wall for the three studied days. When the wall temperature is higher than the air temperature during the period of thermocirculation, buoyancy creates an upward airflow in 


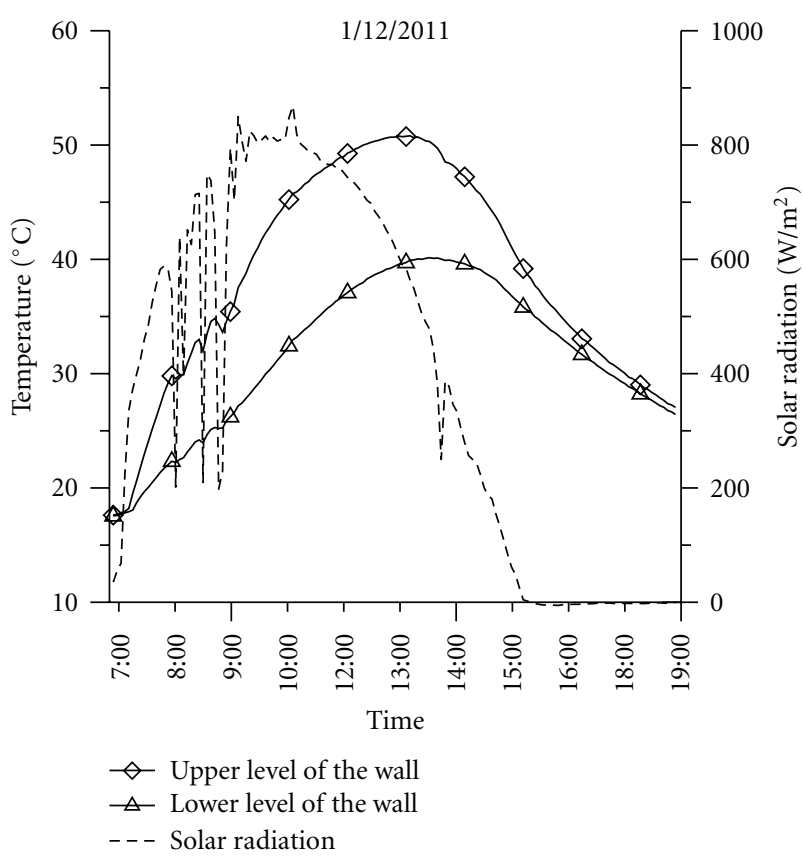

FIGURE 6: Temperature variation at the upper and the lower level of the wall on $1 / 12 / 2011$.

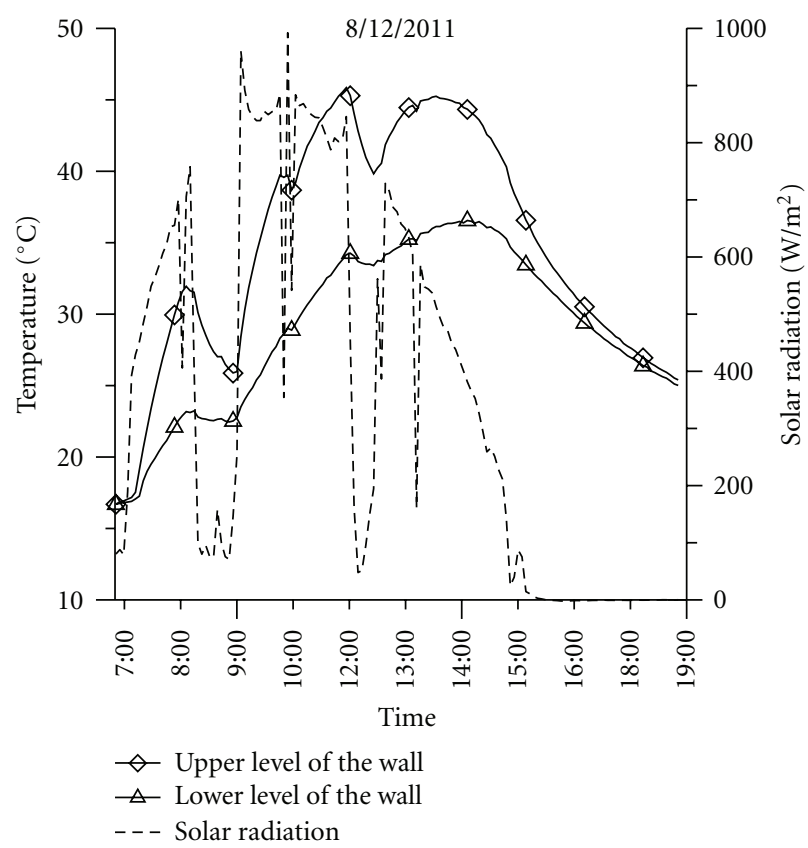

Figure 7: Temperature variation at the upper and the lower level of the wall on $8 / 12 / 2011$.

the channel and the flow passed up the duct close to the higher temperature surface of the darkened wall. In fact, for the 1/12/2011 (Figure 9) and the 14/12/2011 (Figure 11) which are extremely two sunniest days we notice a difference of temperature between the upper level and the lower level of the air gap reaching $7^{\circ} \mathrm{C}$ but for the 8/12/2011 (Figure 10) which is a less sunny day; this difference dropped to $5^{\circ} \mathrm{C}$.

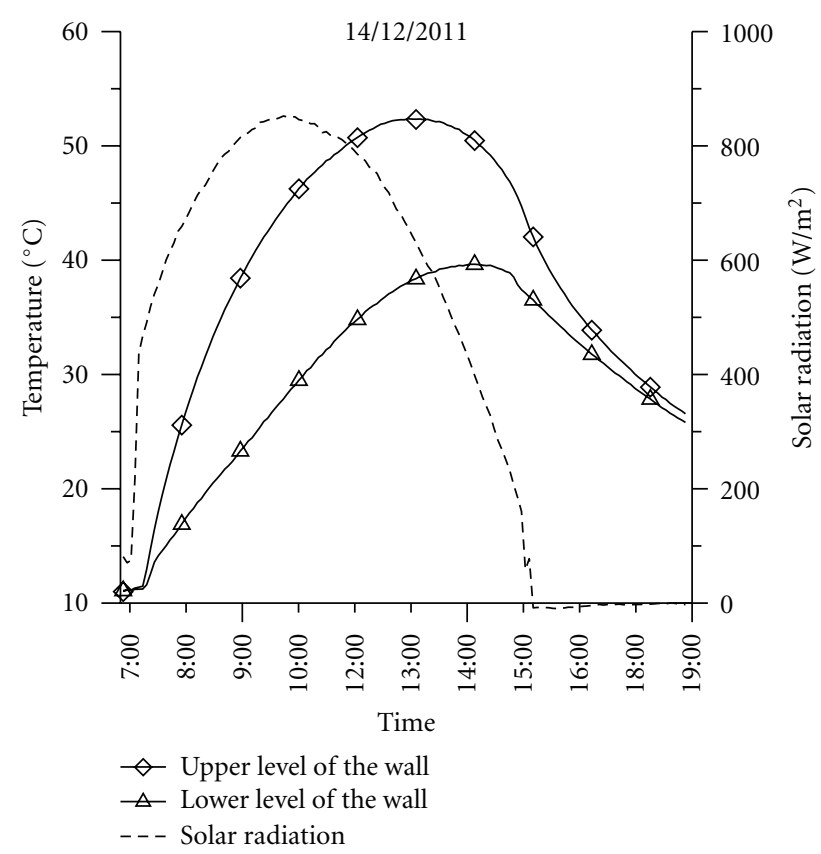

Figure 8: Temperature variation at the upper and the lower level of the wall on $14 / 12 / 2011$.

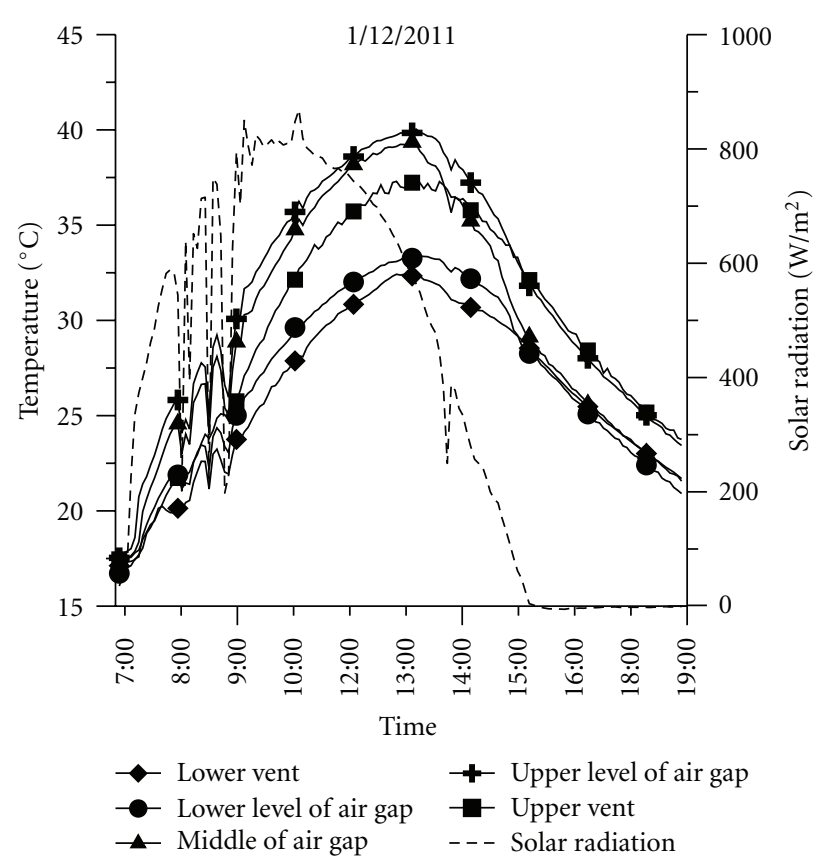

FIGURE 9: Temperature variation at different levels of the air gap on $1 / 12 / 2011$.

It was observed that the air temperature tended to decrease at the upper vent, about $2^{\circ} \mathrm{C}$ for this set of data. This temperature was measured immediately at the upper vent outlet. This drop in the air temperature was attributed to the mixing of the hot air coming from the gap and the ambient air of the test room. 


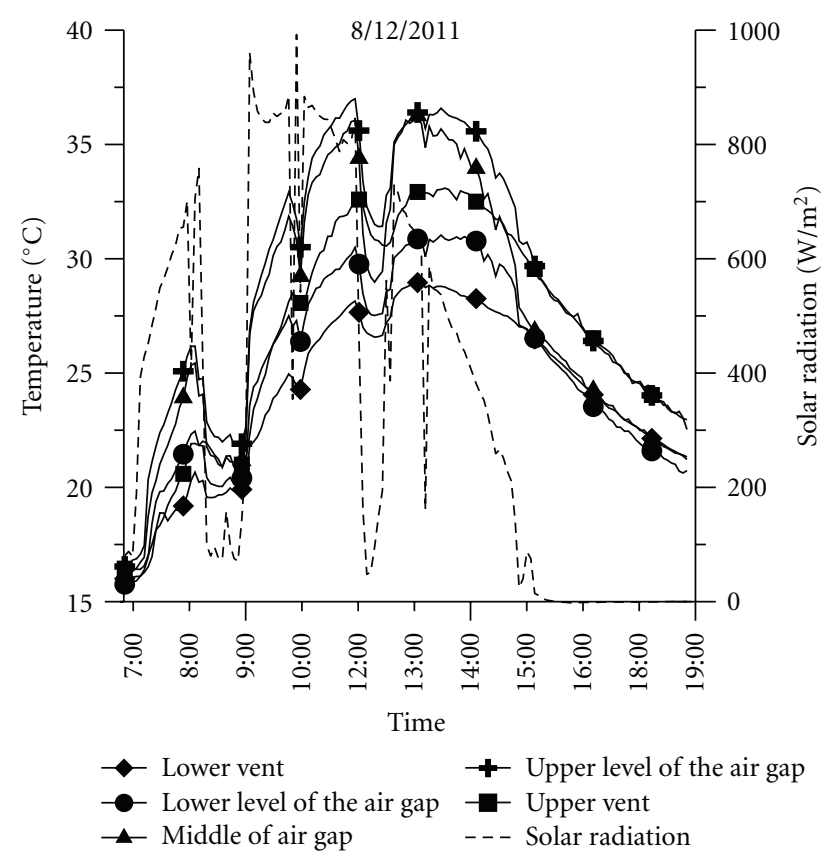

Figure 10: Temperature variation at different levels of the air gap on $8 / 12 / 2011$.

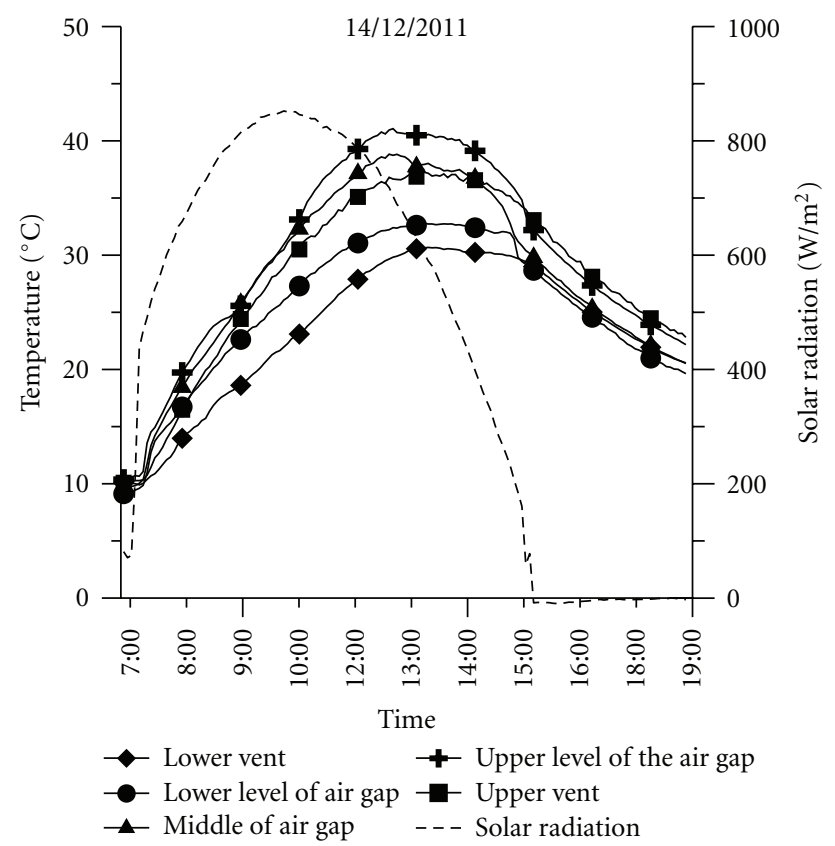

Figure 11: Temperature variation at different levels of the air gap on $14 / 12 / 2011$.

4.5. Effects of Incident Solar Radiation and Air Gap Height. The further investigation was conducted to determine the air gap temperature plotted against air gap height at different solar radiation intensity (Figure 12). The temperature profile in the air gap is an increasing function of gap height and solar radiation. The maximum air temperature was recorded at the air gap upper level $(y=113 \mathrm{~cm})$, it reaches $36.2^{\circ} \mathrm{C}$ for a solar radiation of $868 \mathrm{~W} / \mathrm{m}^{2}$. The net flow is from the gap to the

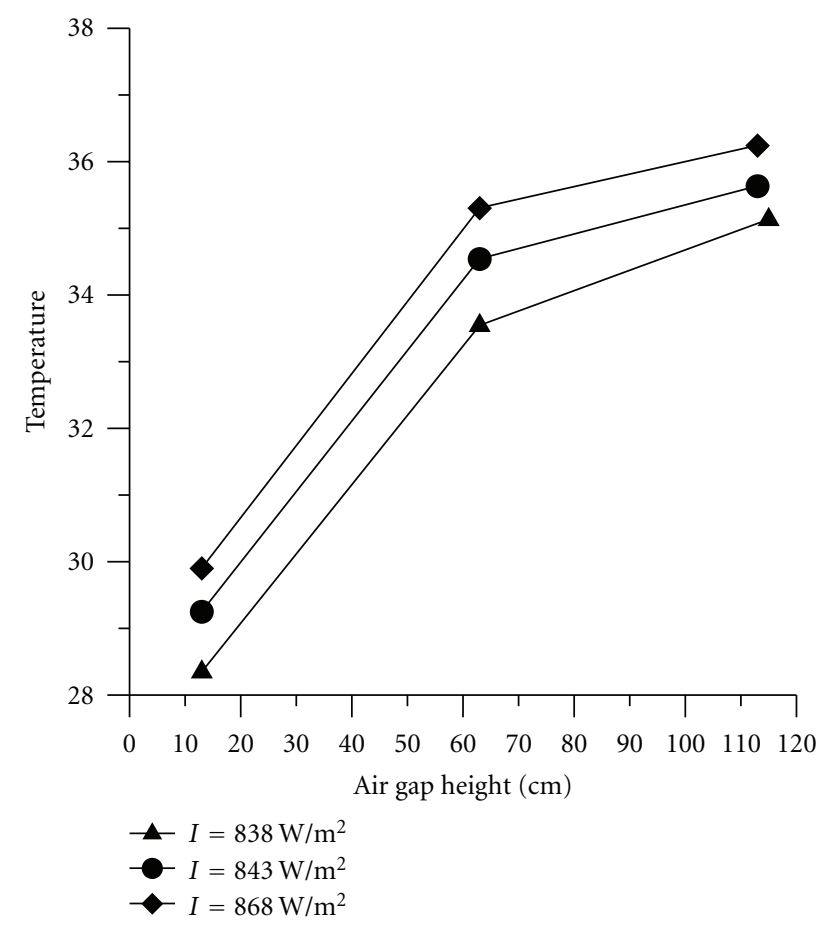

FIGURE 12: Temperature of the air gap at different solar radiation against air gap height.

room through the upper vent indicating that the heat flux from the massivewall offers a useful energy in order to heat the room.

4.6. Convective Heat Transfer Coefficient along the Wall. In normal thermocirculation, the air flows from the gap to the test room, so the airflow in the gap can be regarded as natural convective flow between two vertical parallel plates (wall and glazing). Because the blackened wall is usually at a higher temperature than the glazing, the Grashoff governing the natural convection on the wall side is always higher than that beside the glazing. Figure 13 illustrates the evolution of the experimental Rayleigh number governing the natural convection on the wall for the three different days during the period of thermocirculation when the convection is intensified and on its maximum. At the beginning of the thermocirculation process the flow was laminar $\left(\mathrm{Ra}<10^{9}\right)$ then the transition to turbulent occurs between 8:00 and 9:00. The flow was found to be turbulent $\left(\mathrm{Ra}>10^{9}\right)$ along the entire height of the wall. Consequently, we interest in the turbulent part and use the correlation of Churchill and Chu for turbulent flow $\left(\mathrm{Ra}>10^{9}\right)(10)$, we calculate the Nusselt number illustrated by Figure 14. From this curve we distinguish three clear parts: come up, continuation, and drop. During the come up period and due to the small temperature differences between the air in the gap and the wall surface, the values of Nusselt number are quite small. This period lasts around 2 hours for the three studied days. In continuation period, $\mathrm{Nu}$ keeps steady despite the permanent change in surfaces and air temperature all the 


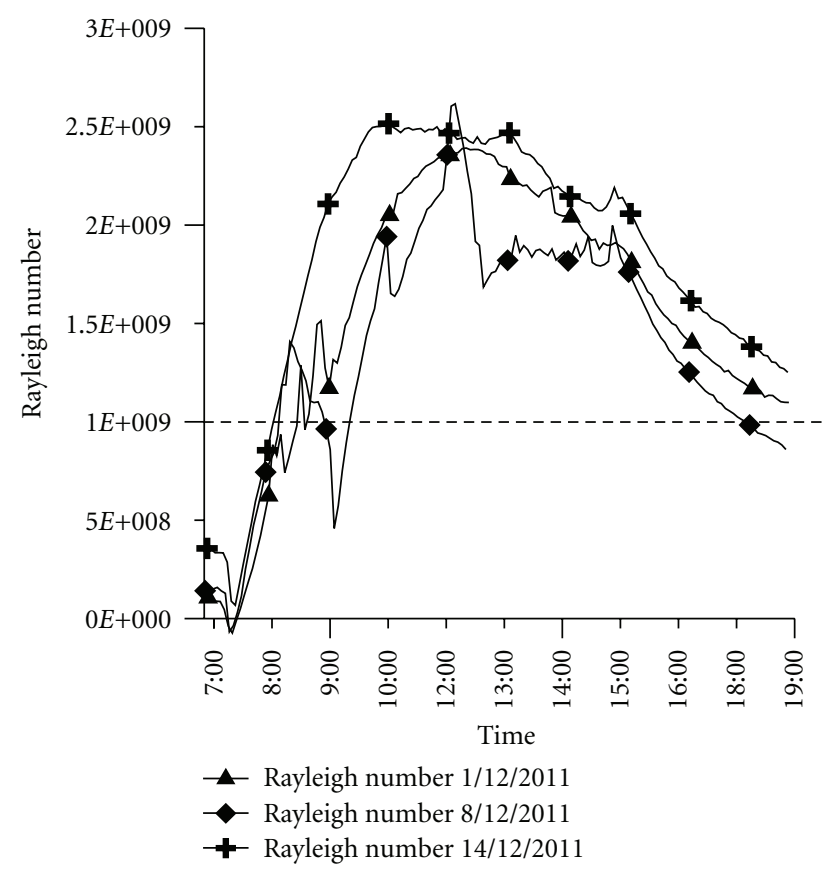

Figure 13: Evolution of Rayleigh number on December 1th, 8th, and 14th 2011.

time. During the test period, the thermocirculation is kept for 5 hours in sunniest days $(1 / 12 / 2011$ and $14 / 12 / 2011)$ as it starts averagely at 10:00 but for the $8 / 12 / 2011$; the continuation period was characterized by some fluctuations this is due to the highly fluctuating nature of solar radiation. The third period (drop) can last for 3.5 hours when the values of Nusselt number decrease progressively. Figure 15 shows the evolution of the convection coefficient along the wall; it has the same progress of the Nusselt number as these two parameters are proportional. Considering the gradual increase of the air gap temperature along the height, the increase in the flow rate allows the improvement of the heat exchange quality between the wall and the air. In addition to the quoted observations, we also notice that during the normal circulation, the value of the convection coefficient on the wall is about $2.5 \mathrm{~W} / \mathrm{m}^{2} \mathrm{~K}$.

4.7. Evolution of the Convective Flux. The net thermocirculation heat transfer was calculated from the measurements of air stream velocity and the air temperature difference between the upper and lower vents. For comparison and in order to study the contribution of the thermocirculation process, the experimental convective flux for December 1th, 8th, and 14th is illustrated in Figure 16.

Over the period of experimentation, the changes in the ambient weather conditions resulted in changes of the thermocirculation heat transfer and in the proportions of the heat transferred from the wall to the test room. In fact, the convective flux on 14/12/2011 was the highest with a maximum of $140 \mathrm{~W}$. The cloudiness effect on the evolution of the convective flux is clear on $8 / 12 / 2011$. For the $1 / 12 / 2011$ the maximum value is about $80 \mathrm{~W}$ at the peak

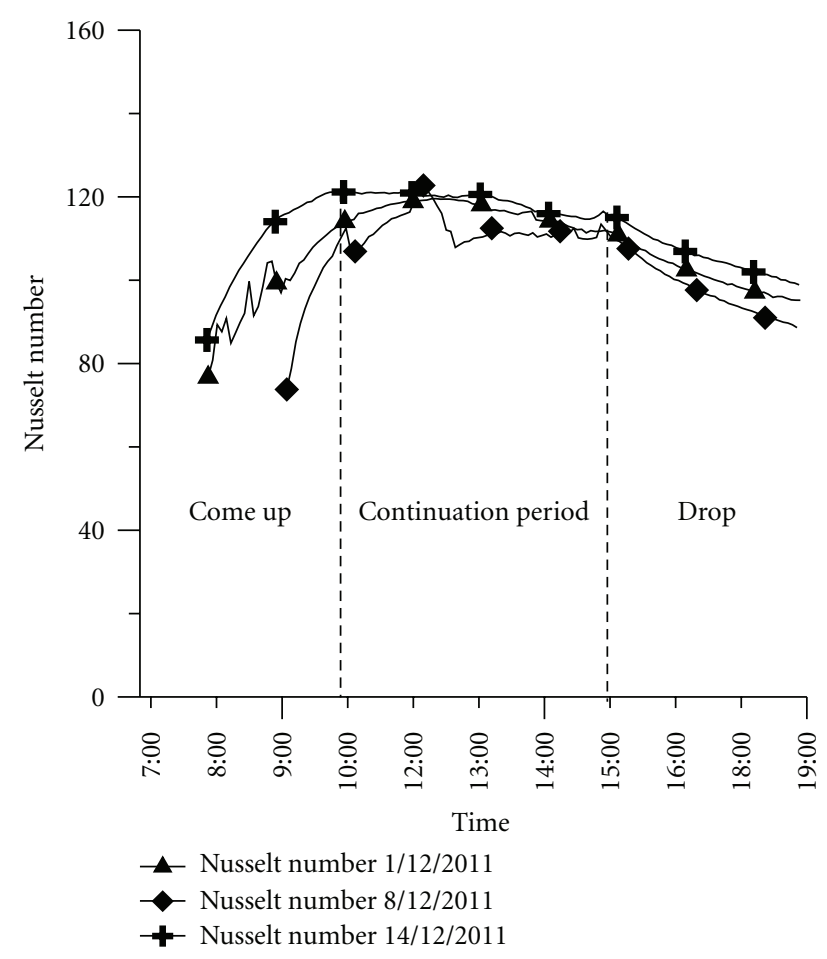

Figure 14: Evolution of Nusselt number on December 1th, 8th, and 14 th 2011.

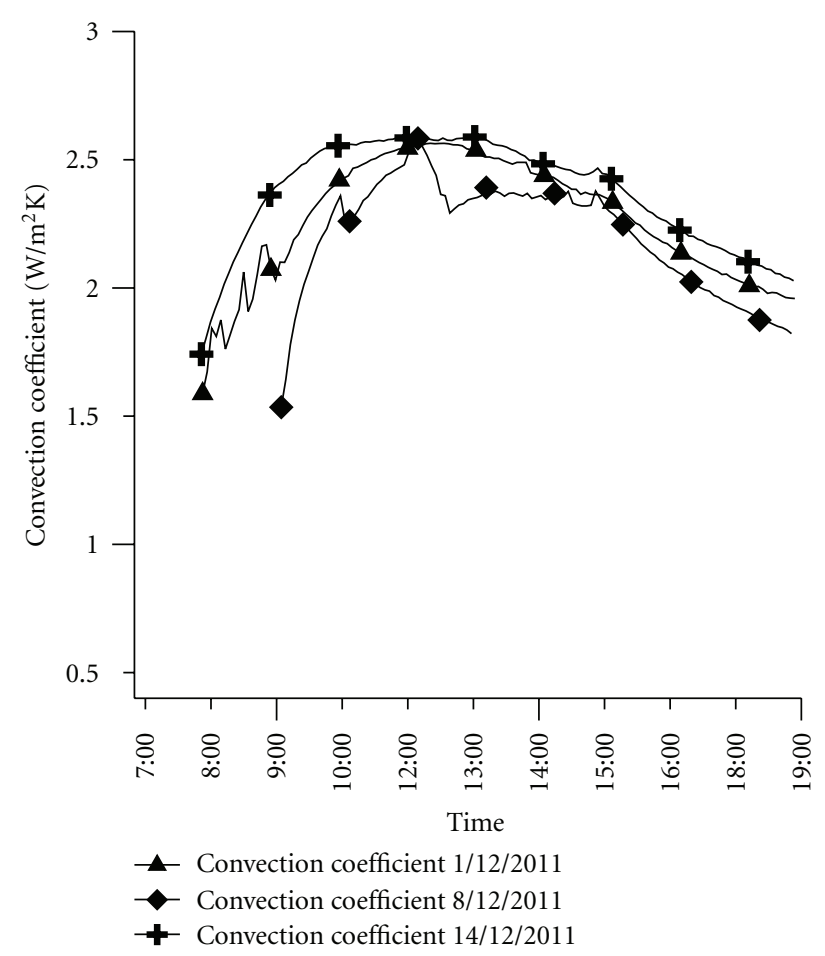

Figure 15: Evolution of convection coefficient of the wall on December 1th, 8th, and 14th 2011. 


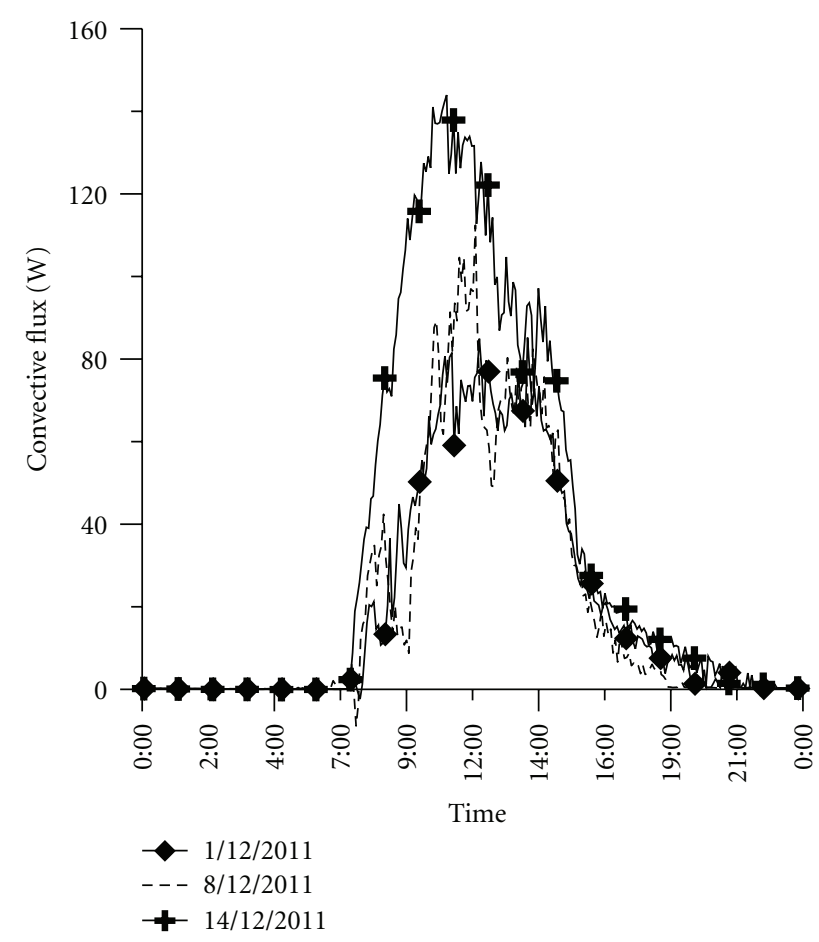

FIgURE 16: Evolution of convective flux on December 1th, 8th, and 14th 2011.

of thermocirculation. As may be seen from Figure 16, for given ambient conditions, the convective flux handled by the air gap increases with increasing solar radiation, and it is superior for higher ambient temperatures.

\section{Conclusion}

Passive solar heating is one of the most economically attractive uses of solar energy. In this context, an experimental study of the thermocirculation characteristics in Trombe wall of a test room was carried out for the first time in Tunisia. There, passive solar buildings with Trombe wall are very interesting for Mediterranean climates with abundant solar radiation in winter. The climatic parameters affecting the operation of the Trombe wall from three different days of three different weeks on December 2011 are used. The effects of the black wall height, the air gap, and the solar radiation on the thermocirculation were studied. The Rayleigh number, Nusselt number, and the convection coefficient of the wall were calculated. In this experiment, the flow pattern of the air gap is composite, with the transition from laminar to turbulent at the beginning, and the airflow was found to be almost turbulent during the period of wall operation. The convective flux was also evaluated from the experimental data. It is efficient to obtain free heating from this wall during the thermocirculation process. This experiment is carried out in a test room with typical construct and geometry parameters, and the natural convection characteristics under different building structures and dimensions and insulation levels still need a further study.

\section{Nomenclature}

$h_{w}$ : Convective heat transfer coefficient between the wall and the fluid $\left(\mathrm{W} / \mathrm{m}^{2} \mathrm{~K}\right)$

$h_{g}$ : Convective heat transfer coefficient between the glazing and the fluid $\left(\mathrm{W} / \mathrm{m}^{2} \mathrm{~K}\right)$

$\mathrm{Nu}_{H w f}$ : Nusselt number between the wall and the fluid

$\mathrm{Nu}_{H g f}$ : Nusselt number between the glazing and the fluid

$\mathrm{Gr}_{w f}$ : Grashof number between the wall and the fluid

$\mathrm{Gr}_{g f}$ : Grashof number between the glazing and the fluid

Ra: $\quad$ Rayleigh number

Pr: $\quad$ Prandtl number

Gr: $\quad$ Grashof number

$T_{u v}$ : Temperature of the air at the upper vent $\left({ }^{\circ} \mathrm{C}\right)$

$T_{l v}$ : Temperature of the air at the lower vent $\left({ }^{\circ} \mathrm{C}\right)$

$T_{w}$ : $\quad$ Temperature of the wall $\left({ }^{\circ} \mathrm{C}\right)$

$T_{g}: \quad$ Temperature of the glazing $\left({ }^{\circ} \mathrm{C}\right)$

$T_{f}$ : Temperature of the fluid in the air gap $\left({ }^{\circ} \mathrm{C}\right)$

$v_{u v}: \quad$ Velocity of the air at the upper vent $(\mathrm{m} / \mathrm{s})$

$v_{l v}$ : Velocity of the air at the lower vent $(\mathrm{m} / \mathrm{s})$

$H$ : Wall height $(\mathrm{m})$

g: $\quad$ Gravitationnel constant $\left(9.8 \mathrm{~m} / \mathrm{s}^{2}\right)$

$C p_{f}: \quad$ Specific heat capacity of the air $(\mathrm{J} / \mathrm{kgK})$

$\mu_{f}: \quad$ Dynamic viscosity of fluid $\left(\mathrm{kgm}^{-1} \mathrm{~s}^{-1}\right)$

$\rho_{f}: \quad$ Density of the fluid $\left(\mathrm{Kg} / \mathrm{m}^{3}\right)$

$\lambda_{f}: \quad$ Thermal conductivity of the fluid $(\mathrm{W} / \mathrm{mK})$

$\beta_{f}$ : Volumetric coefficient of expansion of fluid $\left(\mathrm{K}^{-1}\right)$.

\section{References}

[1] S. B. Sadineni, S. Madala, and R. F. Boehm, "Passive building energy savings: a review of building envelope components," Renewable and Sustainable Energy Reviews, vol. 15, no. 8, pp. 3617-3631, 2011.

[2] H. Y. Chan, S. B. Riffat, and J. Zhu, "Review of passive solar heating and cooling technologies," Renewable and Sustainable Energy Reviews, vol. 14, no. 2, pp. 781-789, 2010.

[3] H. Akbari and T. R. Borgers, "Free convective laminar flow within the Trombe wall channel," Solar Energy, vol. 22, no. 2, pp. 165-174, 1979.

[4] A. G. Fedorov and R. Viskanta, "Turbulent natural convection heat transfer in an asymmetrically heated, vertical parallelplate channel," International Journal of Heat and Mass Transfer, vol. 40, no. 16, pp. 3849-3860, 1997.

[5] W. Aung, L. S. Fletcher, and V. Sernas, "Developing laminar free convection between vertical flat plates with asymmetric heating," International Journal of Heat and Mass Transfer, vol. 15, no. 11, pp. 2293-2308, 1972.

[6] E. M. Sparrow and L. F. A. Azevedo, "Vertical-channel natural convection spanning between the fully-developed limit and the single-plate boundary-layer limit," International Journal of Heat and Mass Transfer, vol. 28, no. 10, pp. 1847-1857, 1985.

[7] R. Anderson and F. Kreith, "Natural convection in active and passive solar thermal systems," Advances in Heat Transfer, vol. 18, pp. 1-86, 1987. 
[8] M. Sandberg and B. Moshfegh, "Investigation of fluid flow and heat transfer in a vertical channel heated from one side by PV elements part II-experimental study," Renewable Energy, vol. 8, no. 1-4, pp. 254-258, 1996.

[9] B. Moshfegh and M. Sandberg, "Investigation of fluid flow and heat transfer in a verticalchannel heated from one side by PV elements part I-numerical study," Renewable Energy, vol. 8, no. 1-4, pp. 248-253, 1996.

[10] B. Chen, H. J. Chen, S. R. Meng, X. Chen, P. Sun, and Y. H. Ding, "The effect of Trombe wall on indoor humid climate in Dalian, China," Renewable Energy, vol. 31, no. 3, pp. 333-343, 2006.

[11] M. S. Sodha, S. C. Kaushik, and J. K. Nayak, "Performance of trombe walls and roof pond systems," Applied Energy, vol. 8, no. 3, pp. 175-191, 1981.

[12] P. Raman, S. Mande, and V. V. N. Kishore, "A passive solar system for thermal comfort conditioning of buildings in composite climates," Solar Energy, vol. 70, no. 4, pp. 319-329, 2001.

[13] G. Gan, "A parametric study of Trombe walls for passive cooling of buildings," Energy and Buildings, vol. 27, no. 1, pp. 3743, 1998.

[14] H. Onbasioglu and A. N. Egrican, "Experimental approach to the thermal response of passive systems," Energy Conversion and Management, vol. 43, no. 15, pp. 2053-2065, 2002.

[15] K. Hami, B. Draoui, and O. Hami, "The thermal performances of a solar wall," Energy, vol. 39, no. 1, pp. 11-16, 2012.

[16] R. O. Warrington and T. A. Ameel, "Experimental studies of natural convection in partitioned enclosures with a Trombe wall geometry," Journal of Solar Energy Engineering, Transactions of the ASME, vol. 117, no. 1, pp. 16-21, 1995.

[17] F. P. Incropera and D. P. DeWitt, Fundamentals of Heat and Mass Transfer, John Wiley \& Sons, New York, NY, USA, 4th edition, 1996.

[18] S. W. Churchill and H. H. S. Chu, "Correlating equations for laminar and turbulent free convection from a vertical plate," International Journal of Heat and Mass Transfer, vol. 18, no. 11, pp. 1323-1329, 1975. 

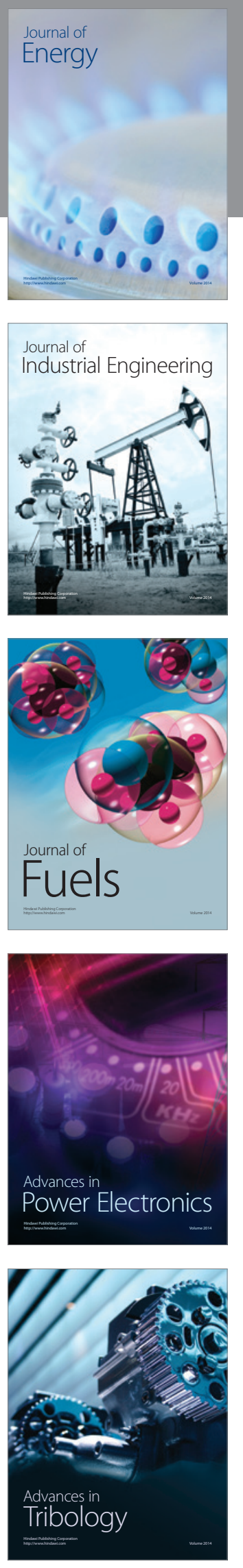
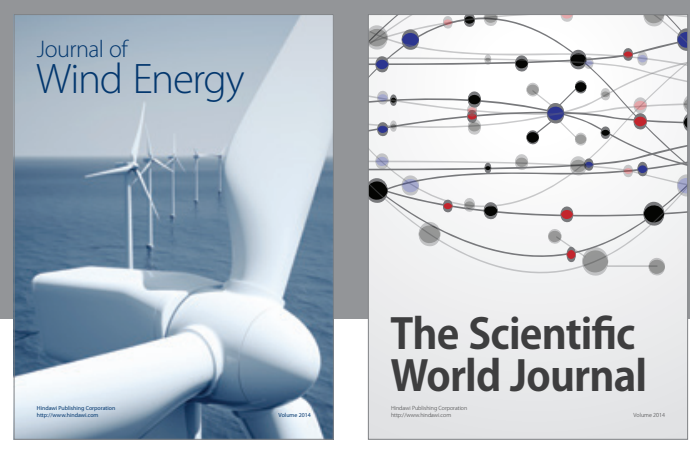

The Scientific World Journal

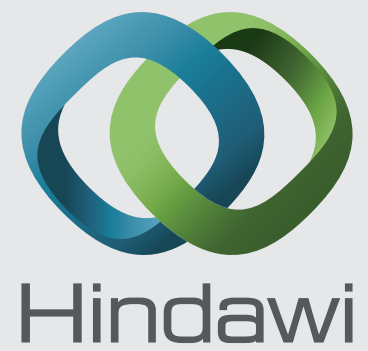

Submit your manuscripts at http://www.hindawi.com
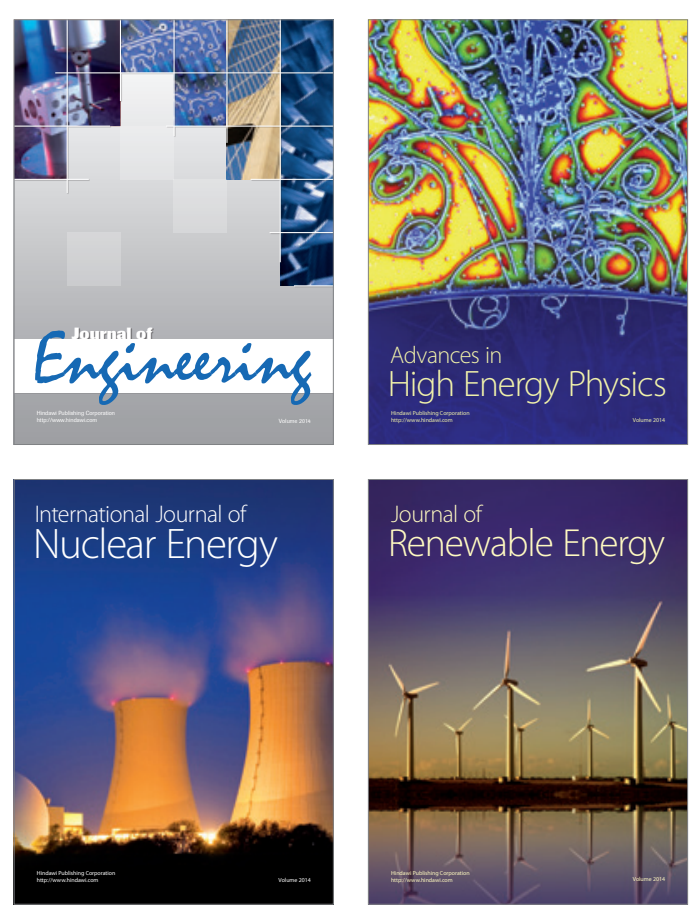

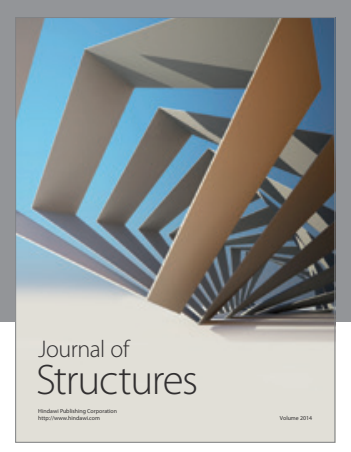

Rotating
Mechinery
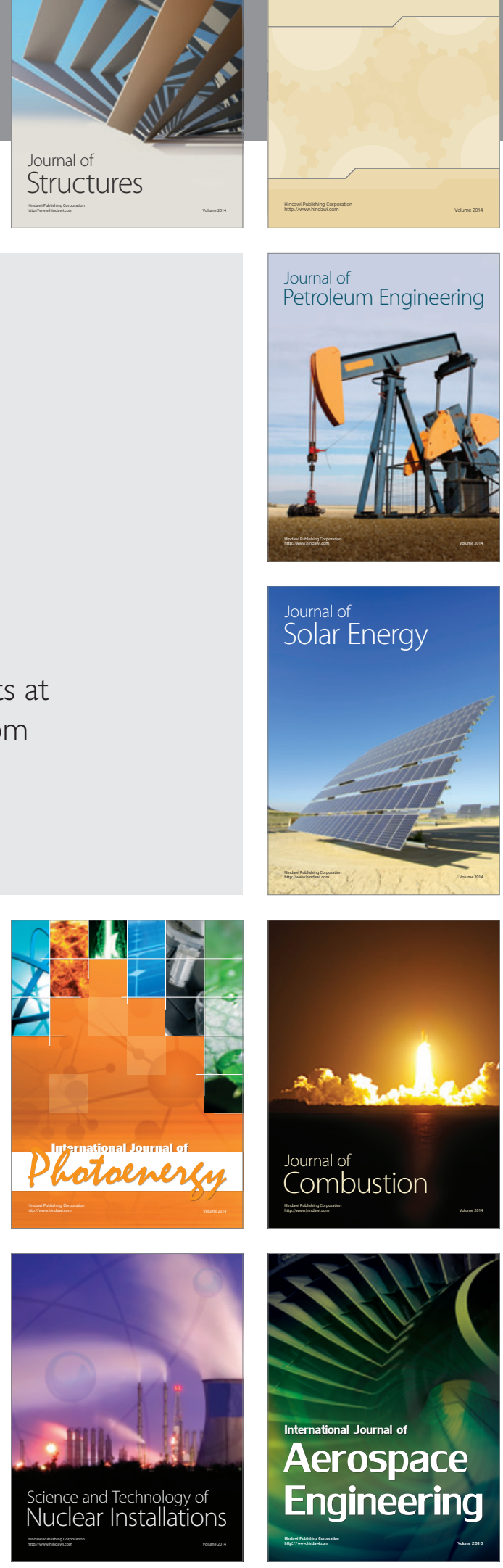